\title{
Efficacy of the Envelope Method in Applying Polyglycolic Acid Sheets to Post-Endoscopic Submucosal Dissection Ulcers in Living Pigs 四
}

\author{
Hiroya Sakaguchi', Toshitatsu Takao', Yoshitaka Takegawa², Yuki Koga², Kazunori Yamanaka², Masataka Sagata², Shinwa Tanaka', \\ Yoshinori Morita', Takashi Toyonaga' and Yuzo Kodama' \\ ${ }^{1}$ Division of Gastroenterology, Department of Internal Medicine, Kobe University Graduate School of Medicine, Kobe, ${ }^{2} \mathrm{KM}$ Biologics \\ Co., Ltd., Kumamoto, Japan
}

Background/Aims: Application of polyglycolic acid (PGA) sheets using fibrin glue in post-endoscopic submucosal dissection (ESD) ulcers to prevent bleeding has been reported to be difficult with the conventional delivery method because of gravity. This study assessed the usefulness of the envelope-based delivery system with and against gravity in living pigs.

Methods: PGA sheets were applied on post-ESD ulcers with and against gravity six times each using the conventional and envelope methods, respectively. The PGA sheet delivery time and the endoscopic and histological findings of the treated ulcer floors were compared.

Results: With gravity, the median PGA sheet application time was $1.00(0.68-1.30) \mathrm{min} / \mathrm{cm}^{2}$ and $0.32(0.18-0.52) \mathrm{min} / \mathrm{cm}^{2}$ with the conventional and envelope techniques $(p=0.002)$, respectively, and against gravity, it was $1.20(1.13-1.63) \mathrm{min} / \mathrm{cm}^{2}$ and $0.50(0.39-$ $0.58) \mathrm{min} / \mathrm{cm}^{2}(p=0.002)$, respectively. Against gravity, the endoscopic and histological findings revealed that the conventional group had insufficient fixation of the PGA sheets, but the envelope groups had sufficient fixation. The results with gravity were similar between the groups.

Conclusions: The envelope method makes it possible to deliver PGA sheets to the stomach quickly and cover ulcers appropriately both with and against gravity in living pigs. Clin Endosc 2021;54:64-72

Key Words: Endoscopic submucosal dissection; Fibrin tissue adhesive; Gastrointestinal hemorrhage; Polyglycolic acid; Stomach

\section{INTRODUCTION}

Endoscopic submucosal dissection (ESD) is widely used as a treatment for gastric cancers that are associated with a low risk of nodal metastasis. However, the prevalence of postoperative bleeding, a complication of ESD, is approximately $0 \%-15.6 \%$

\footnotetext{
Received: January 5, 2020 Revised: March 6, 2020

Accepted: April 7, 2020

Correspondence: Toshitatsu Takao

Division of Gastroenterology, Department of Internal Medicine, Kobe University Graduate School of Medicine, 7-5-2 Kusunoki-cho, Chuo-ku, Kobe 650-0017, Japan

Tel: +81-78-382-6305, Fax: +81-78-382-6309, E-mail: t.takao1234@gmail.com ORCID: https://orcid.org/0000-0002-2595-1772
}

(c) This is an Open Access article distributed under the terms of the Creative Commons Attribution Non-Commercial License (http://creativecommons.org/ licenses/by-nc/3.0) which permits unrestricted non-commercial use, distribution, and reproduction in any medium, provided the original work is properly cited. and it reduces a patient's quality of life. ${ }^{1,2}$ The number of patients receiving antithrombotic agents is expected to increase in the future as the populations age; therefore, there is a concern that the incidence of post-ESD bleeding will also grow. ${ }^{3}$ However, no effective hemostatic methods for preventing such bleeding have been established yet.

Recently, the use of fibrin glue to attach polyglycolic acid (PGA) sheets (Neoveil ${ }^{\circledR}$ 0.15-mm sheets; Gunze Ltd., Osa$\mathrm{ka}$, Japan) to ulcer beds following ESD has been reported as a promising method in preventing post-ESD bleeding. ${ }^{4-8}$ Although this method has already been demonstrated to be useful in many surgical fields, ${ }^{9-12}$ it is difficult to use it to treat post-ESD ulcers in the gastrointestinal tract, especially, when the sheets have to be applied against gravity. Takimoto et al. reported a method for covering post-ESD ulcers with PGA sheets. ${ }^{13}$ However, it requires a long time because the PGA sheets become wet and massive when they are passed one-by- 
one through a forceps channel. Additionally, Takegawa et al. reported that when PGA sheets are delivered and fixed to the stomach they become wet with saliva or mucus, which degrades their adhesive power. ${ }^{14}$ To address these issues, Takao et al. developed an envelope-based system for delivering PGA sheets to the stomach (the envelope method) in $2017 .{ }^{15}$ In this method, PGA sheets are stored in an envelope during their transport, which allows them to be transported and fixed to the stomach rapidly without exposing them to saliva or mucus (Fig. 1A). ${ }^{15}$ Their study revealed that PGA sheets can be efficiently delivered and fixed to the digestive tract. However, this method was only demonstrated to be effective for treating ulcers in resected stomachs when the sheets were applied in the direction of gravity (such ulcers are referred to as gravitational ulcers hereafter); the delivery and fixation of PGA sheets is easy in such ulcers.

It remains unclear whether the envelope method is useful for treating ulcers in the living body and against the direction of gravity (such ulcers are referred to as anti-gravitational ulcers hereafter). This study was performed to demonstrate the usefulness of the envelope method for treating both gravitational and anti-gravitational post-ESD ulcers in living porcine stomachs.

\section{MATERIALS AND METHODS}

This study was approved by KM Biologics institutional animal care and use committee (approval number: B18-024) and was conducted in compliance with the relevant regulations regarding humane treatment of laboratory animals.

The time required to deliver PGA sheets into the stomach of a living pig and fix them in place with or against gravity as part of the treatment of post-ESD ulcers (PGA sheet application time) was compared between the conventional and envelope methods. Additionally, after PGA sheets were fixed in place in the anti-gravitational or gravitational direction with fibrin glue (Bolheal; KM Biologics Co., Ltd., Kumamoto, Japan) using the conventional or envelope method, endoscopic and histological examinations were performed and the results were compared between the methods.

\section{Artificial ulcer creation}

Three male pigs (Large White X Landrace or Large White, age: 2-3 months, body weight: $20-30 \mathrm{~kg}$ ) were used for this study. Tracheal intubation was performed under general anesthesia. An upper gastrointestinal endoscope (GIF-H260; Olympus Co., Tokyo, Japan) was inserted through an overtube (TOP overtube 17, double type; Top Co., Ltd., Tokyo, Japan) into the stomach. Fig. 2. depicts the methods by which PGA sheets were used to cover the ulcers and fixed in place with fibrin glue.

In two living pigs (animals 1 and 2), two anti-gravitational post-ESD ulcers (ulcers 1 and 2) were created in the stomach. Additionally, two gravitational post-ESD ulcers (ulcers 3 and 4) were created in the stomach of another living pig (animal 3) (Fig. 2A). To delineate each ulcer site, a circular piece of paper was placed on the mucosa, and marks were made around the paper to ensure that the ulcer size was constant. Glyceol (Glyceol injection 20 g/200 mL; Chugai Pharmaceutical Co., Ltd., Tokyo, Japan) was locally injected into the marked regions. An electric knife (Flush knife BT ${ }^{\circledR}$, DK2618JB; Fujifilm Co., Tokyo, Japan or IT knife $2^{\circledR}$, KD-611L; Olympus) and an electric generator (ESG-400; Olympus) were used for the ESD.

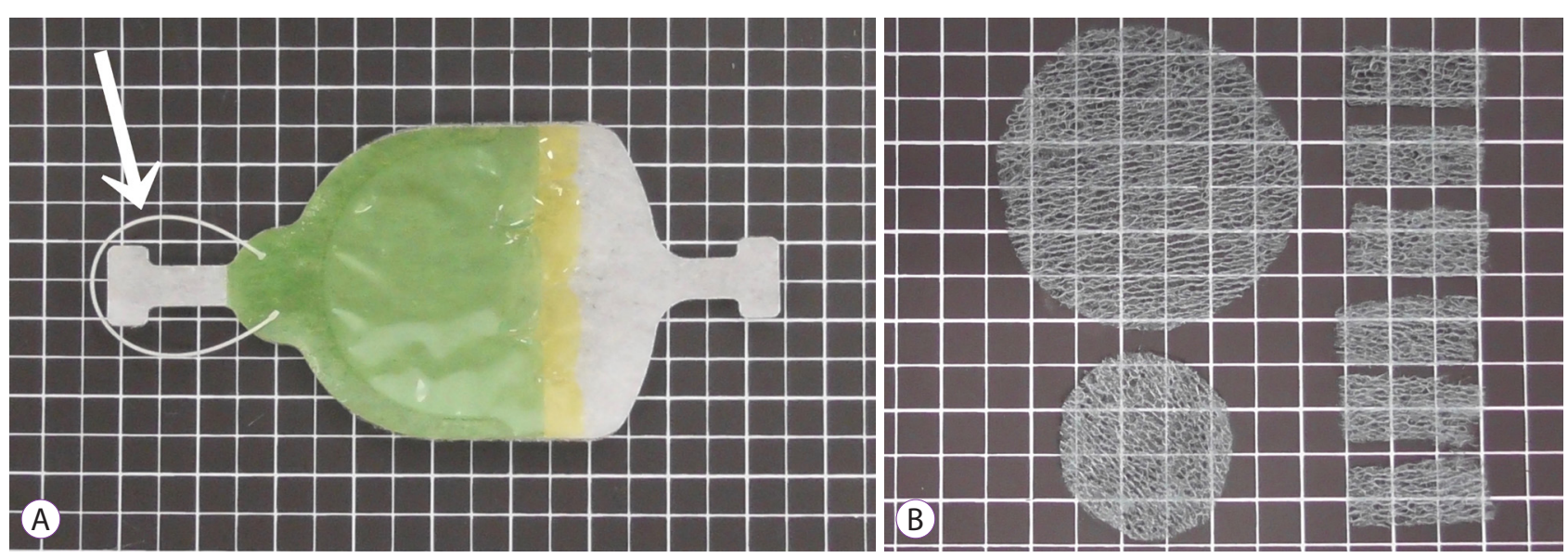

Fig. 1. (A) Bolheal ${ }^{\circledR} \mathrm{Gl}$ envelope (Nipro Co., Osaka, Japan). The radio-opaque string attached to the envelope (white arrow) was held using forceps during the insertion of the envelope. (B) Polyglycolic acid sheets. Three types of sheets, large, medium, and small, were used. 
(A)

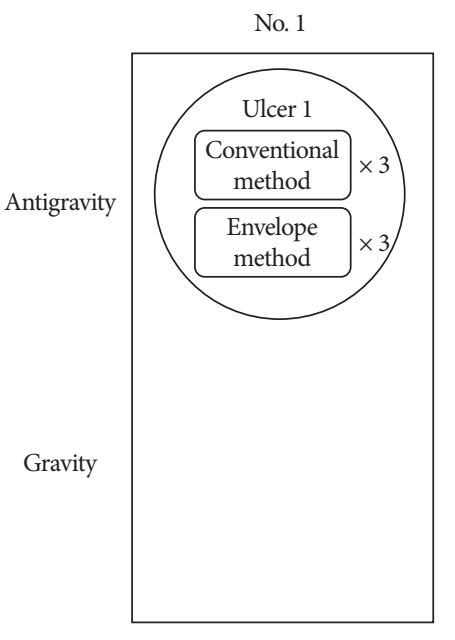

No. 1

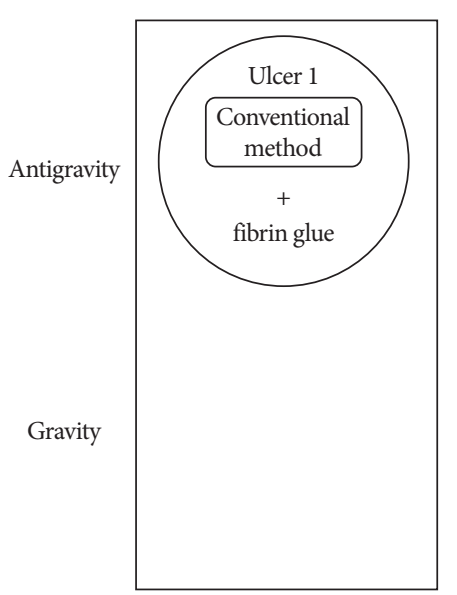

No. 2

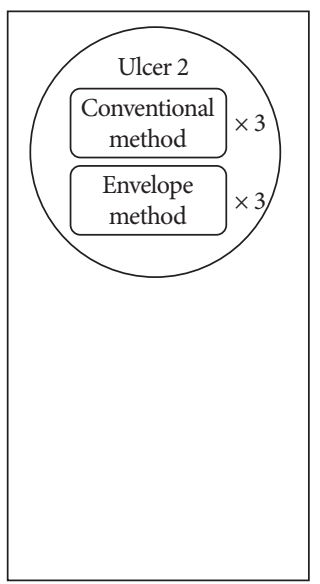

No. 2

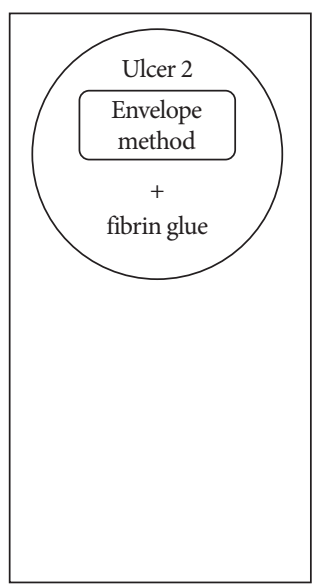

No. 3

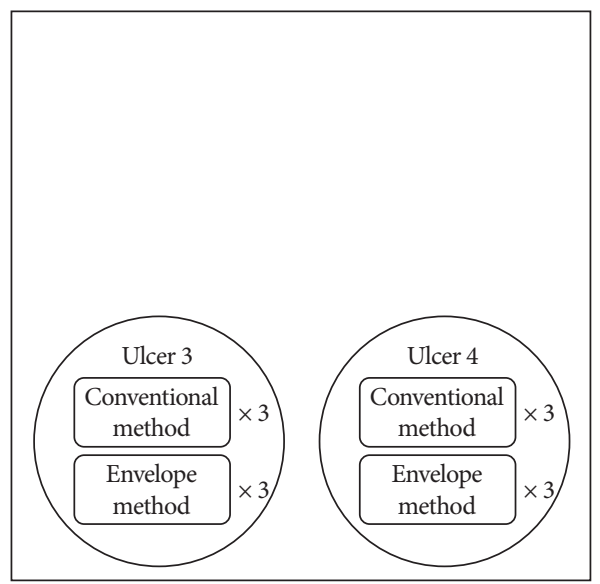

No. 3

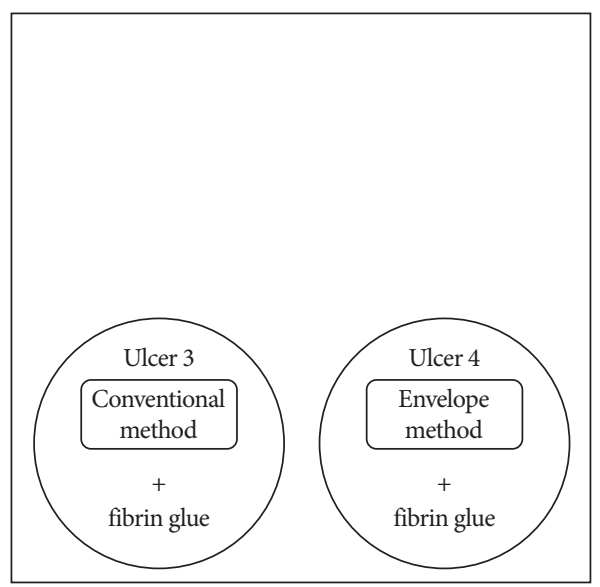

Fig. 2. (A) The method used to apply the polyglycolic acid (PGA) sheets to the ulcers. (B) The method used to fix the PGA sheets to the ulcers using fibrin glue.

After the ESD was completed, the blood vessels in the ulcer floor were coagulated using hemostatic forceps (Coagrasper ${ }^{\circledR}$, FD-411QR; Olympus).

\section{Polyglycolic acid sheet delivery and fixation}

In the conventional method, $15 \times 7$-mm PGA sheets were grasped with biopsy forceps, transported to the stomach oneby-one through a forceps channel, and attached to the ulcer floor, as reported by Takimoto et al. ${ }^{13}$ The forceps used in the conventional method were the same as those used by Takao et al. in 2017 (FB-25K-1; Olympus), which are considered to be less likely to become tangled up in the fibers of the PGA sheets than other types of forceps (Supplementary Video 1)..$^{15}$

In the envelope method, large or medium-sized PGA sheets, which had been cut to match the size of the target ulcer, and $15 \times 7$-mm PGA sheets were placed in a two-layered container envelope (Bolheal ${ }^{\circledR}$ GI envelope; Nipro Co., Osaka, Japan) (Fig. $1 \mathrm{~B})$. Before the endoscope was inserted, the radio-opaque string (Fig. 1A; white arrow) attached to the envelope, which protruded from the tip of the endoscope was grasped using the hemostatic forceps. The envelope body was held with the fingers so that the transparent film was in contact with the endoscope. Lubricating jelly was applied to the absorbent surface of the envelope. The endoscope was inserted through a mouthpiece, and the envelope was passed into the stomach. It was placed on the gravitational side of the stomach so that its absorbent surface adhered tightly to the mucosa. A largeor medium-sized sheet was removed from the envelope using the hemostatic forceps and fixed to the ulcer floor. When an ulcer could not be fully covered using a large sheet, additional small sheets were taken from the envelope and attached to the ulcer site. As the PGA sheets stored in the envelope were less 
likely to become wet and fold, we were able to use hemostatic forceps. Therefore, it was not necessary to change forceps after the post-ESD hemostatic coagulation procedure (Supplementary Video 2).

The two post-ESD ulcers on the gravitational side and the two post-ESD ulcers on the anti-gravitational side were covered repeatedly (three times for each ulcer) with PGA sheets using the conventional or envelope method. Therefore, the time required for the delivery and fixation of the PGA sheets (PGA sheet application time) was measured six times for each method, as depicted in Fig. 2A. To standardize the site and size of ulcers between the two methods, after a PGA sheet had been stuck in place using one method, it was completely removed using the forceps. Subsequently, the other method was used to paste the sheet against the same ulcer. In order to reduce the differences between the application time and condition of the ulcer floor between the conventional method and envelope method due to edema caused by PGA sheet application and detachment, the order of the conventional method and envelope method was changed for each procedure.

\section{Measurements}

PGA sheet application time was defined as the time required to transport the PGA sheets into the stomach and cover the entire ulcer floor. The measurement of the PGA sheet application time started when the tip of the endoscope was placed near the ulcer and the forceps holding the PGA sheet were inserted into the forceps channel in the conventional method, and when the endoscope and envelope passed through the mouthpiece in the envelope method. As it is difficult to create ulcers of the same size and the size of the ulcer changes depending on the volume of air in the stomach, the diameter of each ulcer was measured using a scale (M1-2U; Olympus) before each application procedure, and the application time per unit area was compared. All procedures were performed by a single operator to minimize interoperator differences in the delivery or fixation of the PGA sheets. As the operator was familiar with both methods in advance, any effects of the learning curve were small, but both methods were used alternately to reduce the learning curve effects to the greatest degree possible.

\section{Histological evaluation}

PGA sheets were attached using the conventional or envelope method to anti-gravitational (ulcers 1 and 2) or gravitational (ulcers 3 and 4 ) ulcers. They were then fixed in place with fibrin glue (Fig. 2B). The fibrin glue was applied using a double-lumen catheter (Bolheal ${ }^{\circledR}$ double-lumen catheter; Nipro), which was specifically developed for use during the application of Bolheal ${ }^{\circledR}$. The catheter tip was then used to press the PGA sheet on the ulcer (the force used was not sufficient to displace the PGA sheet) so that solution A permeated the entire sheet. Subsequently, solution B was applied to the ulcer floor similarly. After the sheets were fixed in place, the pigs were immediately euthanized. After the ulcers had been fixed in $10 \%$ neutral buffered formalin, paraffin sections were prepared in the standard manner, stained with hematoxylin and eosin, and evaluated histologically.

\section{Statistics}

Mann-Whitney's $U$ test was used to detect significant differences in the PGA sheet application time. The minimum number of ulcers required was calculated to be six. Results associated with two-tailed $p$-values $<0.05$ were considered to be significant. The effect size was computed based on previous results. ${ }^{15}$ All statistical analyses were conducted using the EZR software (Saitama Medical Center, Jichi Medical University, Saitama, Japan). ${ }^{16}$

\section{RESULTS}

PGA sheet application times for the gravitational ulcers are summarized in Table 1 and Fig. 3A. The application times for the anti-gravitational ulcers are summarized in Table 2 and Fig. 3B.

The median (range) PGA sheet application time per unit area for the gravitational ulcers was $1.00(0.68-1.30) \mathrm{min} /$ $\mathrm{cm}^{2}$ and $0.32(0.18-0.52) \mathrm{min} / \mathrm{cm}^{2}$ in the conventional and envelope approach, respectively. The median PGA sheet application time per unit area in the envelope group for the gravitational ulcers was significantly shorter than that in the conventional group $(p=0.002)$. The median (range) PGA sheet application time per unit area for the anti-gravitational ulcers was $1.20(1.13-1.63) \mathrm{min} / \mathrm{cm}^{2}$ and $0.50(0.39-0.58) \mathrm{min} / \mathrm{cm}^{2}$ in the conventional and envelope approach, respectively. The median PGA sheet application time per unit area in the envelope group for the anti-gravitational ulcers was significantly shorter than that in the conventional group $(p=0.002)$. There was no significant difference in the application time in each group depending on the order of the procedures. Additionally, the application time per unit area in the envelope method was shorter than that in the conventional method in each procedure.

In the endoscopic examinations of the anti-gravitational ulcer sites, the ulcer floor revealed uneven PGA sheets in the conventional group and some PGA sheets had clumped together (Fig. 4A), whereas the endoscopic examinations of the anti-gravitational ulcer sites revealed appropriately applied PGA sheets in the envelope group-the sheets were flat and 
Table 1. The Time Required to Deliver Polyglycolic Acid Sheets and Cover Gravitational Ulcers Using the Two Methods

\begin{tabular}{|c|c|c|c|c|c|}
\hline \multicolumn{6}{|c|}{ Conventional method } \\
\hline $\begin{array}{l}\text { Individual } \\
\text { number }\end{array}$ & $\begin{array}{c}\text { Ulcer } \\
\text { number }\end{array}$ & $\begin{array}{l}\text { Size of mucosal defect } \\
\text { (major×minor axis), cm }\end{array}$ & $\begin{array}{l}\text { Delivery and covering time } \\
(\mathrm{min}, \mathrm{sec})\end{array}$ & $\begin{array}{l}\text { Size of mucosal defect } \\
\left(\mathrm{cm}^{2}\right)\end{array}$ & $\begin{array}{l}\text { Delivery and covering time } \\
\text { per unit area }\left(\mathrm{min} / \mathrm{cm}^{2}\right)\end{array}$ \\
\hline 3 & 3 & $3.0 \times 2.8$ & $4 \min 28 \mathrm{sec}$ & 6.6 & 0.68 \\
\hline 3 & 3 & $2.8 \times 2.8$ & $5 \mathrm{~min} 21 \mathrm{sec}$ & 6.2 & 0.87 \\
\hline 3 & 3 & $2.8 \times 2.8$ & $6 \min 28 \mathrm{sec}$ & 6.2 & 1.05 \\
\hline 3 & 4 & $4.0 \times 2.8$ & $11 \mathrm{~min} 26 \mathrm{sec}$ & 8.8 & 1.30 \\
\hline 3 & 4 & $4.2 \times 2.6$ & $10 \min 16 \mathrm{sec}$ & 8.6 & 1.20 \\
\hline 3 & 4 & $4.5 \times 2.5$ & $8 \mathrm{~min} 25 \mathrm{sec}$ & 8.8 & 0.95 \\
\hline \multicolumn{6}{|c|}{ Envelope method } \\
\hline $\begin{array}{l}\text { Individual } \\
\text { number }\end{array}$ & $\begin{array}{c}\text { Ulcer } \\
\text { number }\end{array}$ & $\begin{array}{l}\text { Size of mucosal defect } \\
\text { (major×minor axis), cm }\end{array}$ & $\begin{array}{l}\text { Delivery and covering time } \\
(\mathrm{min}, \mathrm{sec})\end{array}$ & $\begin{array}{l}\text { Size of mucosal defect } \\
\left(\mathrm{cm}^{2}\right)\end{array}$ & $\begin{array}{l}\text { Delivery and covering time } \\
\text { per unit area }\left(\mathrm{min} / \mathrm{cm}^{2}\right)\end{array}$ \\
\hline 3 & 3 & $3.3 \times 3.0$ & $1 \mathrm{~min} 33 \mathrm{sec}$ & 7.8 & 0.20 \\
\hline 3 & 3 & $2.8 \times 2.8$ & $2 \mathrm{~min} 07 \mathrm{sec}$ & 6.2 & 0.34 \\
\hline 3 & 3 & $3.0 \times 3.0$ & $1 \mathrm{~min} 18 \mathrm{sec}$ & 7.1 & 0.18 \\
\hline 3 & 4 & $4.5 \times 3.1$ & $3 \mathrm{~min} 14 \mathrm{sec}$ & 11.0 & 0.30 \\
\hline 3 & 4 & $4.5 \times 3.0$ & $4 \min 20 \mathrm{sec}$ & 10.6 & 0.41 \\
\hline 3 & 4 & $4.5 \times 2.7$ & $5 \mathrm{~min} 00 \mathrm{sec}$ & 9.5 & 0.52 \\
\hline
\end{tabular}

Table 2. The Time Required to Deliver Polyglycolic Acid Sheets and Cover Anti-Gravitational Ulcers Using the Two Methods

\begin{tabular}{|c|c|c|c|c|c|}
\hline \multicolumn{6}{|c|}{ Conventional method } \\
\hline $\begin{array}{l}\text { Individual } \\
\text { number }\end{array}$ & $\begin{array}{c}\text { Ulcer } \\
\text { number }\end{array}$ & $\begin{array}{l}\text { Size of mucosal defect } \\
\text { (major } \times \text { minor axis), } \mathrm{cm}\end{array}$ & $\begin{array}{l}\text { Delivery and covering time } \\
(\mathrm{min}, \mathrm{sec})\end{array}$ & $\begin{array}{l}\text { Size of mucosal defect } \\
\left(\mathrm{cm}^{2}\right)\end{array}$ & $\begin{array}{l}\text { Delivery and covering time } \\
\text { per unit area }\left(\mathrm{min} / \mathrm{cm}^{2}\right)\end{array}$ \\
\hline 1 & 1 & $3.6 \times 3.3$ & $11 \mathrm{~min} 07 \mathrm{sec}$ & 9.3 & 1.19 \\
\hline 1 & 1 & $3.7 \times 3.0$ & $9 \min 52 \mathrm{sec}$ & 8.7 & 1.13 \\
\hline 1 & 1 & $4.1 \times 3.0$ & $11 \mathrm{~min} 42 \mathrm{sec}$ & 9.7 & 1.21 \\
\hline 2 & 2 & $3.6 \times 3.2$ & $14 \mathrm{~min} 42 \mathrm{sec}$ & 9.0 & 1.63 \\
\hline 2 & 2 & $3.6 \times 3.6$ & $15 \mathrm{~min} 55 \mathrm{sec}$ & 10.2 & 1.56 \\
\hline 2 & 2 & $4.0 \times 3.9$ & $14 \mathrm{~min} 07 \mathrm{sec}$ & 12.2 & 1.15 \\
\hline \multicolumn{6}{|c|}{ Envelope method } \\
\hline $\begin{array}{c}\text { Individual } \\
\text { number }\end{array}$ & $\begin{array}{c}\text { Ulcer } \\
\text { number }\end{array}$ & $\begin{array}{l}\text { Size of mucosal defect } \\
\text { (major } \times \text { minor axis), } \mathrm{cm}\end{array}$ & $\begin{array}{l}\text { Delivery and covering time } \\
(\mathrm{min}, \mathrm{sec})\end{array}$ & $\begin{array}{l}\text { Size of mucosal defect } \\
\left(\mathrm{cm}^{2}\right)\end{array}$ & $\begin{array}{l}\text { Delivery and covering time } \\
\text { per unit area }\left(\mathrm{min} / \mathrm{cm}^{2}\right)\end{array}$ \\
\hline 1 & 1 & $3.6 \times 3.3$ & $4 \min 41 \mathrm{sec}$ & 9.3 & 0.50 \\
\hline 1 & 1 & $3.8 \times 3.3$ & $4 \mathrm{~min} 52 \mathrm{sec}$ & 9.8 & 0.49 \\
\hline 1 & 1 & $4.3 \times 3.6$ & $7 \mathrm{~min} 06 \mathrm{sec}$ & 12.2 & 0.58 \\
\hline 2 & 2 & $4.5 \times 3.9$ & $6 \mathrm{~min} 38 \mathrm{sec}$ & 13.8 & 0.48 \\
\hline 2 & 2 & $4.2 \times 4.0$ & $5 \mathrm{~min} 07 \mathrm{sec}$ & 13.2 & 0.39 \\
\hline 2 & 2 & $4.2 \times 3.7$ & $6 \mathrm{~min} 56 \mathrm{sec}$ & 12.2 & 0.57 \\
\hline
\end{tabular}




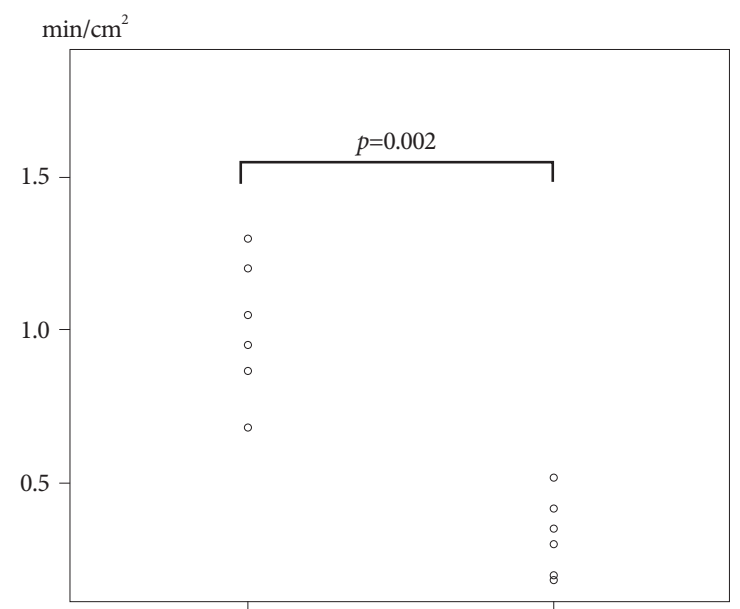

(A)
Conventional method

Envelope method

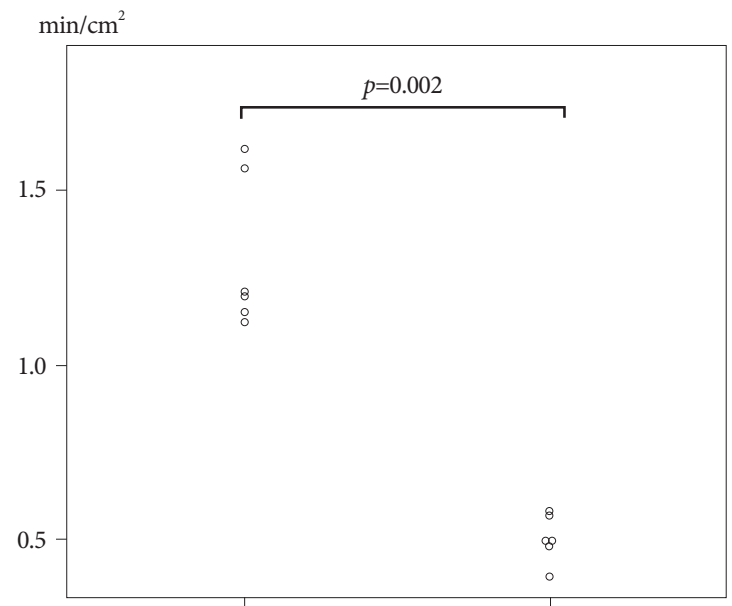

(B)
Conventional method Envelope method

Fig. 3. (A) Dot charts depicting the polyglycolic acid (PGA) sheet application time per square centimeter for gravitational ulcers in the conventional and envelope groups. (B) Dot charts depicting the PGA sheet application time per square centimeter for anti-gravitational ulcers in the conventional and envelope groups.
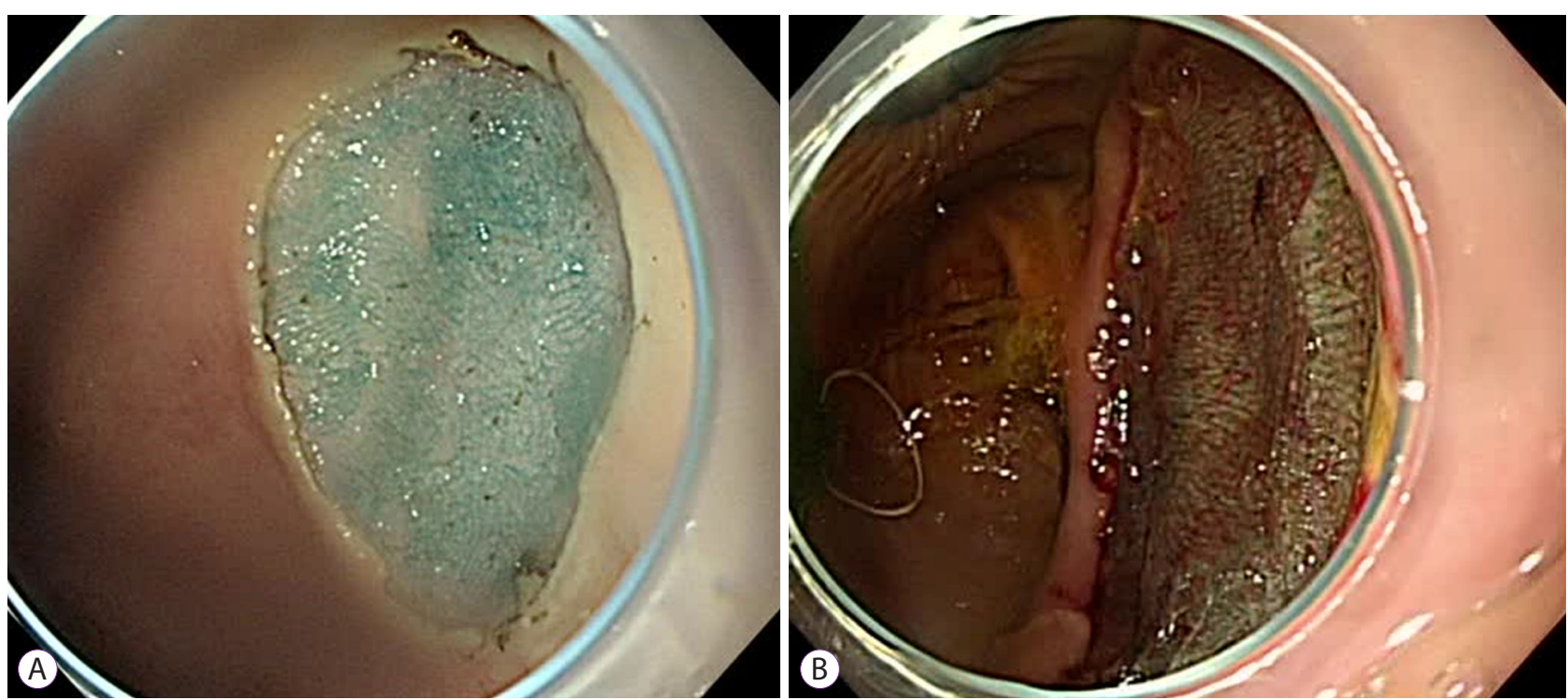

Fig. 4. (A) Endoscopic findings in anti-gravitational ulcers that were covered with polyglycolic acid (PGA) sheets using the conventional method. (B) Endoscopic findings in anti-gravitational ulcers that were covered with PGA sheets using the envelope method.

only slight overlapping of the sheets was seen in all six procedures (Fig. 4B).

Histological examinations of the anti-gravitational ulcer treated using the conventional method revealed that the ulcer floor was partly uncovered because there were gaps between the PGA sheets (Fig. 5A). On the other hand, histological examinations of the anti-gravitational ulcers treated using the envelope method demonstrated that the ulcer floor was uniformly covered with a mixture of PGA sheets and fibrin glue (Fig. 5B). In the anti-gravitational ulcers treated using the envelope method, the thickness of one layer of PGA sheets/fibrin glue was approximately $300 \mu \mathrm{m}$. 

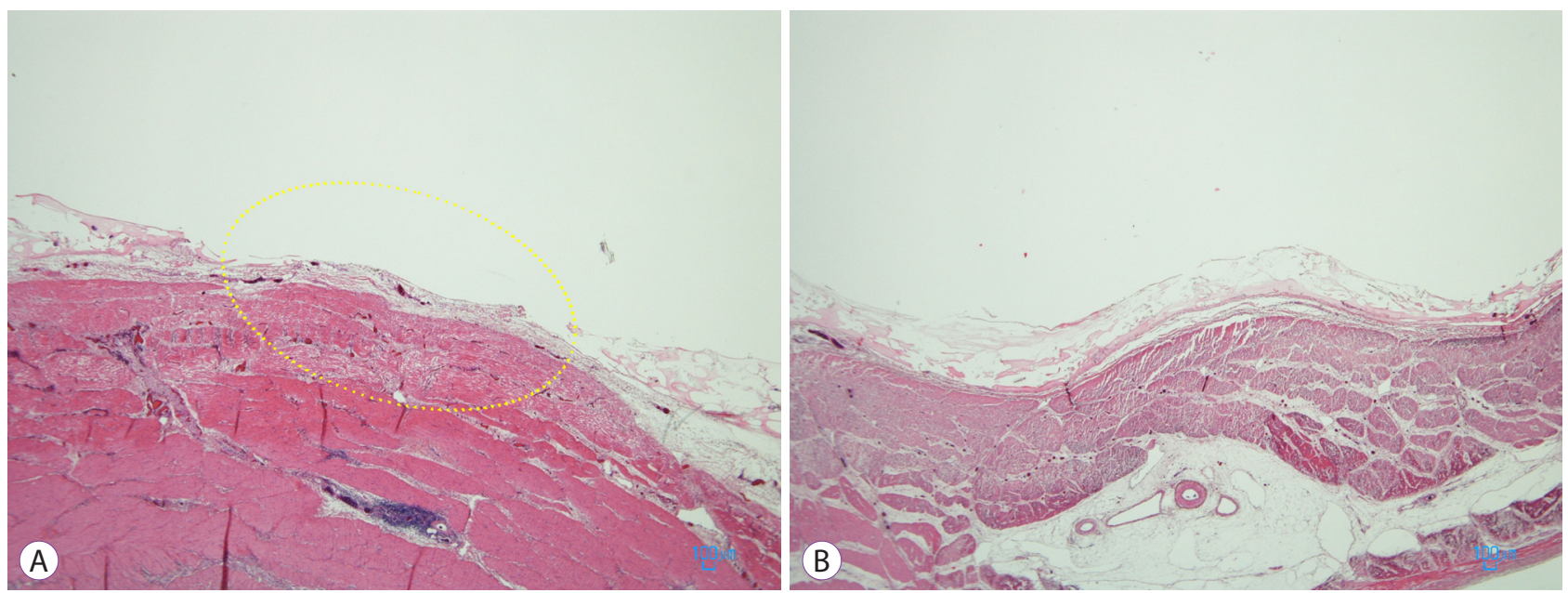

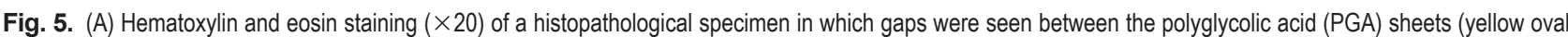
dotted line) that were fixed to an anti-gravitational ulcer site using the conventional method. (B) Hematoxylin and eosin staining $(\times 20)$ of a histopathological specimen in which there were no gaps between the PGA sheets that were fixed to an anti-gravitational ulcer site using the envelope method.

\section{DISCUSSION}

In this study, three important findings were observed in in vivo experiments. First, the PGA sheets were transported and fixed to the anti-gravitational ulcers significantly more quickly in the envelope group than they were in the conventional group. Second, in the envelope group, endoscopic examinations revealed that the sheets were fixed to the anti-gravitational ulcers appropriately, i.e., they laid flat across the ulcer sites without gaps between the sheets. Third, histological examinations confirmed that the sheets were fixed in the anti-gravitational ulcers appropriately in the envelope group.

As mentioned above, PGA sheets were transported and fixed to the gravitational ulcers significantly more quickly in the envelope group than that in the conventional group. In clinical practice, PGA sheets are often fixed to ulcers using the conventional method after ESD. ${ }^{13,17,18}$ However, as indicated above, it takes longer time to apply the sheets in the conventional method because they get wet. Particularly, fixing PGA sheets to the anti-gravitational ulcer sites was more difficult using the conventional method because the sheets that had formed a wet mass in the forceps channel tended to drop downwards due to their weight. In the envelope group, several PGA sheets, including large sheets, were transported into the stomach in a dry state. Therefore, it was possible to quickly fix them in place, even in anti-gravitational ulcers, which was difficult in the past.

Regarding our second finding, in the envelope group, endoscopic examinations demonstrated that the sheets were appropriately fixed on the anti-gravitational ulcer sites under dry conditions, i.e., when the sheets were not exposed to saliva or mucus in vivo. A previous study demonstrated that when exposed to saliva or mucus, fibrin glue does not permeate PGA sheets, thereby, reducing their adherence to the ulcer floor. ${ }^{14} \mathrm{In}$ 2015, Takao et al. transported PGA sheets packaged in folded films into the gastrointestinal tract in living pigs. ${ }^{19}$ However, in some cases the PGA sheets became moist during their transportation. ${ }^{19}$ In contrast, in the envelope group in the present study, all of the transported sheets were delivered without becoming wet, thus, indicating that the envelope method is more effective than the conventional method at protecting PGA sheets from saliva and mucus. The current study demonstrated that PGA sheets can be delivered to the stomach in a dry state, even in vivo.

As for our third finding, in the envelope group, histological examinations demonstrated that PGA sheets were appropriately fixed to the anti-gravitational ulcer sites. As the sheets were light when they were dry, large sheets could be fixed appropriately to the ulcer sites without any wrinkles. When fibrin glue is spread on anti-gravitational ulcer floors, one concern is that it might be difficult to ensure that a sufficient amount of fibrin glue remains on the ulcer floor because of the effects of gravity on the liquid glue. In the present study, the PGA sheet/ fibrin glue layers covering the anti-gravitational ulcer treated using the envelope method were $300-\mu \mathrm{m}$ thick. The PGA sheets used in this study were only $150-\mu \mathrm{m}$ thick. Therefore, it was demonstrated that a sufficient amount of the fibrin glue was retained.

Since 2012, when Takimoto et al. reported a method for applying PGA sheets to duodenal ESD ulcers using fibrin 
glue, several proposals have been made regarding the delivery of PGA sheets to the gastrointestinal tract. ${ }^{13,15,18,20-22}$ Of those methods, the only device delivery station system (DDSS) except for the envelope method may be capable of delivering and pasting PGA sheets into the stomach without exposure to saliva or gastric juice. However, it was reported that some ring-shaped threads need to be tied to the PGA sheet before using the DDSS delivery system. The DDSS must be clipped onto the gastric mucosa before removing the PGA sheets from it. In contrast, we can easily remove the PGA sheet from the envelope without such accessories as the thread on the PGA sheet. Furthermore, we do not have to clip the envelope on the gastric mucosa because the envelope tends to become more adhesive to the mucosa due to the water-absorbing material on the back surface of the envelope. We believe that the envelope method is more useful and secure delivery system to allow PGA sheets to be applied to post-ESD ulcer without exposure of saliva or mucus.

We must ultimately demonstrate whether the application of PGA sheets can prevent the complications of post-ESD bleeding and perforation. However, in order to verify whether PGA sheets are useful in preventing these complications, it is a precondition that the PGA sheets can be delivered to the ESD site efficiently and attached securely on the ulcer floor in vivo. We demonstrated that the envelope method allows PGA sheets to be applied to post-ESD ulcers not only with gravity but also against gravity faster and more securely than the conventional method in living pigs.

\section{Future prospects}

The recent increases in the number of patients taking oral antithrombotic drugs and the number of endoscopic procedures in patients who are on antithrombotic drugs have raised concerns about the frequency of bleeding after endoscopic treatment. The envelope we used in this study has completed the pharmaceutical approval process and is now entering the preparatory stages of commercialization. The envelope method should be examined in a clinical trial to determine whether reliable transportation can be achieved irrespective of the location of the ulcer. Ultimately, a trial will be needed to demonstrate whether shielding with PGA sheets can prevent complications, such as postoperative bleeding and delayed perforation after ESD.

\section{Limitations}

The examinations were conducted by a single operator who was skilled in the procedure. Additionally, the structures of porcine and human stomachs differ slightly. Future clinical trials involving multiple endoscopists should be conducted at multiple facilities.
The envelope method can be used to rapidly transport PGA sheets into living porcine stomachs and fix them in place appropriately. This method can be used to treat both gravitational and anti-gravitational ulcers.

\section{Conflicts of Interest}

Yoshitaka Takegawa, Yuki Koga, Kazunori Yamanaka, Masataka Sagata work for KM Biologics Co., Ltd. The other authors have no potential conflicts of interest.

Funding

This research was conducted as a collaborative effort between Kobe University and KM Biologics Co., Ltd.

Author Contributions

Conceptualization: Hiroya Sakaguchi, Toshitatsu Takao, Yoshitaka Takegawa, Yuki Koga, Kazunori Yamanaka, Masataka Sagata

Data curation: HS, TTa, YT, YKog, KY, MS

Formal analysis: HS, TTa, YT, YKog, KY, MS

Funding acquisition: HS, TTa, YT, YKog, KY, MS

Investigation: HS, TTa, YT, YKog, KY, MS

Methodology: HS, TTa, YT, YKog, KY, MS

Project administration: HS, TTa, YT, YKog, KY, MS

Resources: HS, TTa, YT, YKog, KY, MS

Software: HS, TTa, YT, YKog, KY, MS

Supervision: HS, TTa, YT, YKog, KY, MS, Shinwa Tanaka, Yoshinori Morita, Takashi Toyonaga, Yuzo Kodama

Validation: HS, TTa, YT, YKog, KY, MS, ST, YM, TTo, YKod

Visualization: HS, TTa, YT, YKog, KY, MS, ST, YM, TTo, YKod

Writing-original draft: HS, TTa, YT, YKog, KY, MS

Writing-review\&editing: HS, TTa, YT, YKog, KY, MS, ST, YM, TTo, YKod

\section{ORCID}

Hiroya Sakaguchi:

Toshitatsu Takao:

Yoshitaka Takegawa:

Yuki Koga:

Kazunori Yamanaka:

Masataka Sagata:

Shinwa Tanaka:

Yoshinori Morita:

Takashi Toyonaga:

Yuzo Kodama: https://orcid.org/0000-0002-1212-1905 https://orcid.org/0000-0002-2595-1772 https://orcid.org/0000-0002-8082-0628 https://orcid.org/0000-0001-6031-363X https://orcid.org/0000-0002-3361-5007 https://orcid.org/0000-0003-1201-5528 https://orcid.org/0000-0002-3714-8565 https://orcid.org/0000-0002-5400-3296 https://orcid.org/0000-0003-1226-6749 https://orcid.org/0000-0003-1223-7147
Supplementary Materials

Video 1. Conventional method for covering anti-gravitational ulcers using polyglycolic acid sheets (https://doi.org/10.5946/ce.2020.014.v001).

Video 2. Envelope method for covering anti-gravitational ulcers using polyglycolic acid sheets (https://doi.org/10.5946/ce.2020.014.v002).

\section{REFERENCES}

1. Oda I, Suzuki H, Nonaka S, Yoshinaga S. Complications of gastric endoscopic submucosal dissection. Dig Endosc 2013;25(Suppl 1):71-78.

2. Kataoka Y, Tsuji Y, Sakaguchi Y, et al. Bleeding after endoscopic submucosal dissection: risk factors and preventive methods. World J Gastroenterol 2016;22:5927-5935. 
3. Sato C, Hirasawa K, Koh R, et al. Postoperative bleeding in patients on antithrombotic therapy after gastric endoscopic submucosal dissection. World J Gastroenterol 2017;23:5557-5566.

4. Oda I, Nonaka S, Abe S, Suzuki H, Yoshinaga S, Saito Y. Is there a need to shield ulcers after endoscopic submucosal dissection in the gastrointestinal tract? Endosc Int Open 2015;3:E152-E153.

5. Kawata N, Ono H, Takizawa K, et al. Efficacy of polyglycolic acid sheets and fibrin glue for prevention of bleeding after gastric endoscopic submucosal dissection in patients under continued antithrombotic agents. Gastric Cancer 2018;21:696-702.

6. Fukuda H, Yamaguchi N, Isomoto $\mathrm{H}$, et al. Polyglycolic acid felt sealing method for prevention of bleeding related to endoscopic submucosal dissection in patients taking antithrombotic agents. Gastroenterol Res Pract 2016;2016:1457357.

7. Iizuka T, Kikuchi D, Hoteya S, Kajiyama Y, Kaise M. Polyglycolic acid sheet and fibrin glue for preventing esophageal stricture after endoscopic submucosal dissection: a historical control study. Dis Esophagus 2017;30:1-8.

8. Tsuji Y, Fujishiro M, Kodashima S, et al. Polyglycolic acid sheets and fibrin glue decrease the risk of bleeding after endoscopic submucosal dissection of gastric neoplasms (with video). Gastrointest Endosc 2015;81:906-912.

9. Takeuchi J, Suzuki H, Murata M, et al. Clinical evaluation of application of polyglycolic acid sheet and fibrin glue spray for partial glossectomy. J Oral Maxillofac Surg 2013;71:e126-e131.

10. Kawai H, Harada K, Ohta H, Tokushima T, Oka S. Prevention of alveolar air leakage after video-assisted thoracic surgery: comparison of the efficacy of methods involving the use of fibrin glue. Thorac Cardiovasc Surg 2012;60:351-355.

11. Hayashibe A, Sakamoto K, Shinbo M, Makimoto S, Nakamoto T. New method for prevention of bile leakage after hepatic resection. J Surg Oncol 2006;94:57-60.

12. Sugawara T, Itoh Y, Hirano Y, et al. Novel dural closure technique using polyglactin acid sheet prevents cerebrospinal fluid leakage after spinal surgery. Neurosurgery 2005;57(4 Suppl):290-294; discussion 290-294.

13. Takimoto K, Toyonaga T, Matsuyama K. Endoscopic tissue shielding to prevent delayed perforation associated with endoscopic submucosal dissection for duodenal neoplasms. Endoscopy 2012;44(Suppl 2):E414-E415.

14. Takegawa Y, Takao T, Ono H. [Fundamental examination into the use of fibrin glue and polyglycolic acid sheets as a method for covering postESD ulcers]. Gastroenterological Endoscopy 2015;57:1150-1157.

15. Takao T, Takegawa Y, Ono H, et al. A novel and effective delivery method for polyglycolic acid sheets to post-endoscopic submucosal dissection ulcers. Endoscopy 2017;49:359-364.

16. Kanda Y. Investigation of the freely available easy-to-use software 'EZR' for medical statistics. Bone Marrow Transplant 2013;48:452-458.

17. Tsuji Y, Ohata K, Gunji T, et al. Endoscopic tissue shielding method with polyglycolic acid sheets and fibrin glue to cover wounds after colorectal endoscopic submucosal dissection (with video). Gastrointest Endosc 2014;79:151-155

18. Doyama H, Tominaga K, Yoshida N, Takemura K, Yamada S. Endoscopic tissue shielding with polyglycolic acid sheets, fibrin glue and clips to prevent delayed perforation after duodenal endoscopic resection. Dig Endosc 2014;26(Suppl 2):41-45.

19. Takao T, Takegawa Y, Shinya N, Tsudomi K, Oka S, Ono H. Tissue shielding with polyglycolic acid sheets and fibrin glue on ulcers induced by endoscopic submucosal dissection in a porcine model. Endosc Int Open 2015;3:E146-E151.

20. Sakaguchi Y, Tsuji Y, Ono S, et al. Polyglycolic acid sheets with fibrin glue can prevent esophageal stricture after endoscopic submucosal dissection. Endoscopy 2015;47:336-340.

21. Kumagai K, Iwamoto S, Esaka N, Mizumoto Y. A new method of polyglycolic acid sheet placement in the stomach after endoscopic submucosal dissection. Endoscopy 2016;48(Suppl 1):E274-E275.

22. Mori H, Guan Y, Kobara H, et al. Efficacy of innovative polyglycolic acid sheet device delivery station system: a randomized prospective study. Surg Endosc 2018;32:3076-3086. 